\title{
Real-SOFC - A Joint European Effort to Improve SOFC Durability
}

Steinberger-Wilckens, Robert; Bucheli, Olivier; De Haart, L.G.J.; Hagen, Anke; Kiviaho, Jari; Larsen, Jørgen G.; Pyke, Stephen; Rietveld, B. G.; Sfeir, Josef; Tietz, Frank

\author{
Published in: \\ E C S Transactions \\ Link to article, DOI: \\ 10.1149/1.3205507 \\ Publication date: \\ 2009
}

Document Version

Publisher's PDF, also known as Version of record

Link back to DTU Orbit

Citation (APA):

Steinberger-Wilckens, R., Bucheli, O., De Haart, L. G. J., Hagen, A., Kiviaho, J., Larsen, J. G., Pyke, S.,

Rietveld, B. G., Sfeir, J., \& Tietz, F. (2009). Real-SOFC - A Joint European Effort to Improve SOFC Durability. E C S Transactions, 25(2), 43-56. https://doi.org/10.1149/1.3205507

\section{General rights}

Copyright and moral rights for the publications made accessible in the public portal are retained by the authors and/or other copyright owners and it is a condition of accessing publications that users recognise and abide by the legal requirements associated with these rights.

- Users may download and print one copy of any publication from the public portal for the purpose of private study or research.

- You may not further distribute the material or use it for any profit-making activity or commercial gain

- You may freely distribute the URL identifying the publication in the public portal 


\title{
Real-SOFC - A Joint European Effort to Improve SOFC Durability
}

\author{
R. Steinberger-Wilckens ${ }^{a}$, O. Bucheli ${ }^{\text {, }}$ L.G.J. de Haart ${ }^{\mathrm{a}}$, A. Hagen ${ }^{\mathrm{c}}$, J. Kiviaho ${ }^{\mathrm{d}}$

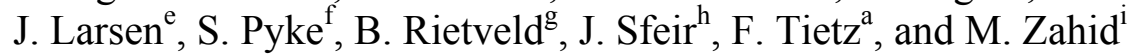 \\ ${ }^{a}$ Forschungszentrum Jülich, Institute of Energy Research, D-52425 Jülich, Germany \\ ${ }^{\mathrm{b}}$ HTceramix, CH-1400 Yverdon-les-Bains, Switzerland \\ ${ }^{c}$ Risø-DTU, Fuel Cells and Solid State Chemistry Division, DK-4000 Roskilde, Denmark \\ ${ }^{\mathrm{d}}$ VTT Technical Research Centre of Finland, FI-02044 VTT Espoo, Finland \\ ${ }^{\mathrm{e}}$ Topsø Fuel Cells, DK-2800 Lyngby, Denmark \\ ${ }^{\mathrm{f}}$ RollsRoyce Fuel Cell Systems, Derby DE24 8BJ, Great Britain \\ ${ }^{\mathrm{g}}$ Energy Research Centre ECN, Fuel Cell Technologies Unit \\ NL-1755 ZG Petten, The Netherlands \\ ${ }^{\mathrm{h}}$ HEXIS AG, CH-8404 Winterthur, Switzerland \\ ${ }^{\mathrm{i}}$ EIfER, European Institute for Energy Research, D- 76131 Karlsruhe, Germany
}

The Integrated Project Real-SOFC joined 26 partners from throughout Europe active in SOFC technology. The project was funded by the European Commission within the 6th Framework Programme and aimed at improving the durability of planar SOFC stacks to degradation rates of well below $1 \%$ per 1000 hours of operation. This is an essential requirement in gaining access to the market for stationary applications. The underlying idea was to improve materials and materials processing on the basis of extensive test results identifying degradation mechanisms, and then to supply industrial components of enhanced quality for repeated testing analysis. This 'feedback loop' resulted in ' 2 ' ', and ' 3 rd, Generations of SOFC components. This paper summarises the project approach, shows examples of the major results and of longterm durability testing.

\section{Introduction and Project Outline}

Twenty-six partners from the European fuel cell industry, research institutions and universities were involved in the European 6th Framework Integrated Project Real-SOFC from 2004 to 2008. The project aimed at finding ways to reduce degradation in SOFC, both by improving the understanding of degradation processes and simultaneously using that knowledge iteratively in developing improved materials and concepts resulting in extended lifetimes of stacks. The knowledge gained was directly implemented by the industrial and manufacturing partners to deliver improved, industrial-standard components for renewed testing. The goal was to increase reliable lifetime of stacks to well above 10000 hours in order to qualify stacks for stationary applications. Further attention was given to the 'robustness' of stacks, referring to increasing the tolerance towards sulphur content in the fuel, for thermal and redox cycling, and extending operation towards lower steam to carbon ratios - all of which works towards simplifying the operation of SOFC systems and improving the 'ruggedness' of stacks under transient and sub-optimal conditions that may arise in everyday operation. 
Over the project lifetime, 2 generations of improvements were implemented. Starting from experiments with state-of-the-art (SotA, 'G1') components of 2004, these were extended to 'Generation 2' and 'Generation 3' (G2 and G3, respectively) as materials and components with improved performance became available and/or identified. By the end of 2008 two G3 stacks fulfilled the proof-of-concept long-term test goal of 10000 hours of operation.

\section{Testing Conditions}

A total of 100 test-rig-years was available in the project for sharing the task of testing four different stack concepts: Rolls Royce Fuel Cell Systems' integrated planar concept, the HEXIS seal-less design, the HTCeramix compressive seal stacks and the Forschungszentrum Jülich (FZJ) sealed planar stacks. These are all shown in Fig. 1. Since it had to ensured that cell and stack testing at the various testing laboratories would render comparable results, standard test procedures were agreed and coordinated with the FCTESTnet project. This resulted in a baseline test defined as $500 \mathrm{~mA} / \mathrm{cm}^{2}$ current density at $700 \mathrm{mV}$, fuel utilisation $\left(\mathrm{u}_{\mathrm{F}}\right)$ of $40 \%$ and $800^{\circ} \mathrm{C}$ operating temperature; tests were to run over 3000 hours as a standard duration. Deviations from the current setting were accepted for components not able to supply this current at a minimum of $700 \mathrm{mV}$.
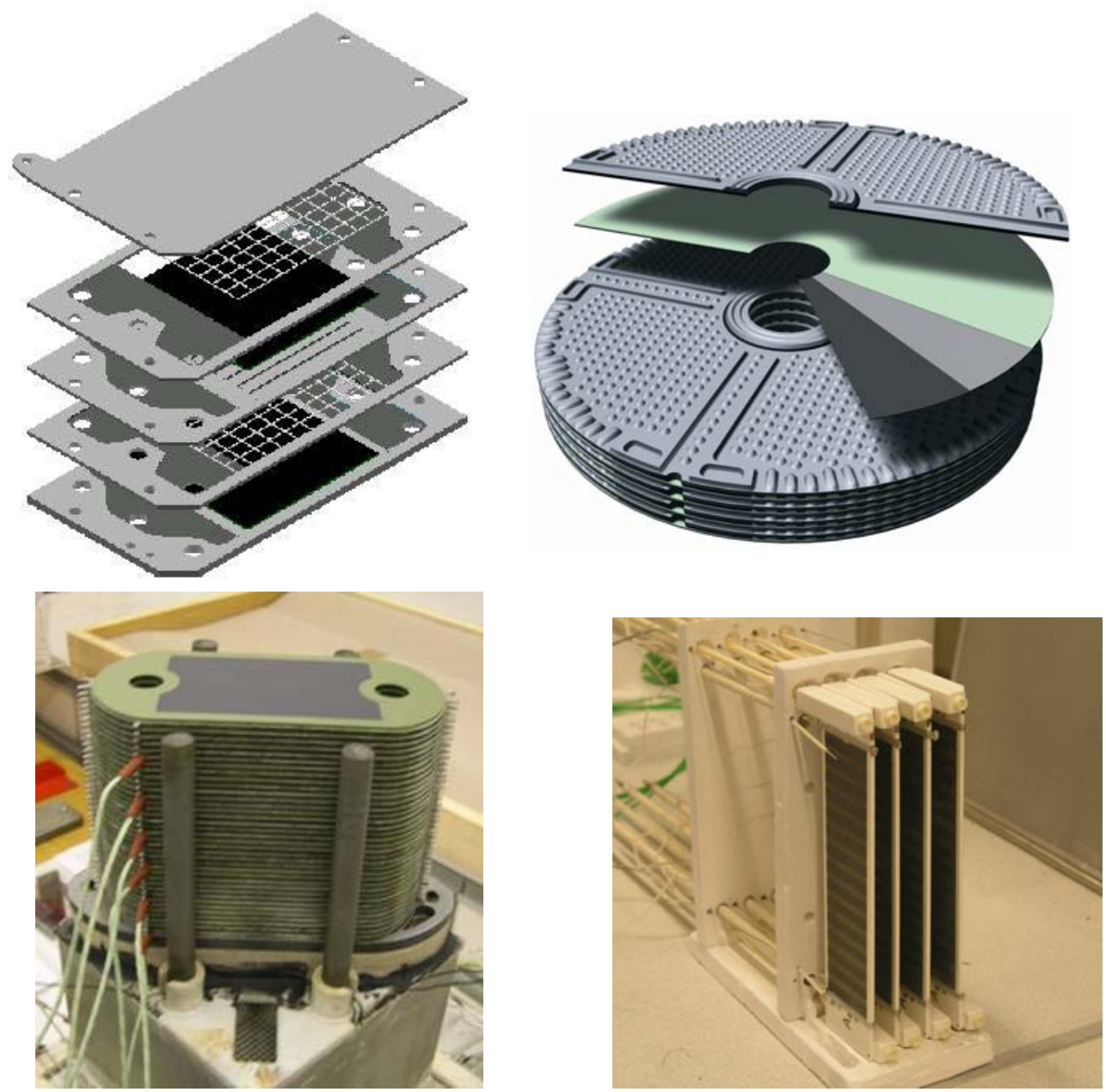

Figure 1. The four types of stacks subjected to long-term tests within Real-SOFC: clockwise from top left: FZJ F1002 2-cell short stack, HEXIS unsealed stack, RollsRoyce Fuel Cell Systems 4-tube bundle, HTceramix S-design sealed stack. 
After one year of operation, though, it was found that these conditions were too mild to give clear evidence of degradation mechanisms, ever after 3000 hours. Therefore it was suggested to the consortium to use more 'severe' testing conditions that would aggravate degradation, so that cause and effect could more readily be put into relation. Interestingly, a poll amongst SOFC system developing industry showed that these companies preferred very 'mild' test conditions in order to prolong stack lifetime as much as possible and deliver high efficiencies. The more severe conditions adopted in Real-SOFC constituted more of a benchmark than 'realistic' conditions.

Whilst these conditions were used to establish improvements from changes in the materials set, two other standard tests were agreed: the proof-of-concept (long-term) test for 10000 hours at the initial standard conditions $\left(500 \mathrm{~mA} / \mathrm{cm}^{2}\right)$ and the 'Sensitivity Matrix' which looked into the dependency of degradation rate on the parameters current density, fuel utilisation, temperature and fuel.

Within this testing matrix current density was selected in the band from 300 to 700 $\mathrm{mA} / \mathrm{cm}^{2}$ and fuel utilisation between 10 and $75 \%$. Temperatures were set at 700 and $800^{\circ} \mathrm{C}$ and experiments run both with hydrogen and methane internal reforming. FZJ stacks were chosen as a reference technology due to the wealth of experience and data already acquired at the more moderate end of the parameter scale. The more demanding settings could readily be added to the existing data. Covering the main part of the matrix within the project was only possible by shared testing between project partners VTT, CEA, EBZ and FZJ. The initial round of testing showed that the stacks had a fully reproducible performance and could be securely transported to the various testing sites.

\section{FZJ Technology}

At Forschungszentrum Jülich standard anode substrate type cells with LSM cathodes were used in the F-design G1 short stacks (2 cell stacks) (1). The second generation of stacks was manufactured with interconnects made of Plansee ITM steel using an adapted glass sealant and protective/contact coatings and LSM-cathode cells. The third received LSCF cathodes along with the corresponding contact layer.

A variant of the G3 stack (G3-TK) was manufactured using the CroFer22APU steel (with the appropriate protective coatings and glass sealing).

Performance tests on the two candidate G3 short stacks showed an ASR of all cells of about $0.26 \Omega \cdot \mathrm{cm}^{2}$ at $700^{\circ} \mathrm{C}$. It was agreed that the $\mathrm{G} 3$ stacks should be run at the same power level as the G2, using the temperature for adjustment. Incidentally it turned out that the temperature could be lowered to $700^{\circ} \mathrm{C}$. After the durability tests on both short stacks successfully passed $3000 \mathrm{~h}$, the tests were continued with the aim to reach $10000 \mathrm{~h}$ of operation which was accomplished at the end of 2008. Over the first $3000 \mathrm{~h}$ of operation a degradation rate of $22 \mathrm{~m} \Omega \cdot \mathrm{cm}^{2} / \mathrm{kh}$ was determined for both cells in the G3 stack, corresponding to $0.75 \%$ voltage degradation per 1000 hours of operation. Stack G3-TK showed slightly higher degradation.

Figure 3 shows a selection of results from the sensitivity matrix tests. Comparison of the top curve (also depicted in Figure 2) with stacks run at higher current density but 
same temperature (bottom curve) and a stack run at high current and high temperature (middle curve) indicate that the temperature is of more of an influence on the absolute rate of degradation than the current density. The graph also shows that the relative rate of

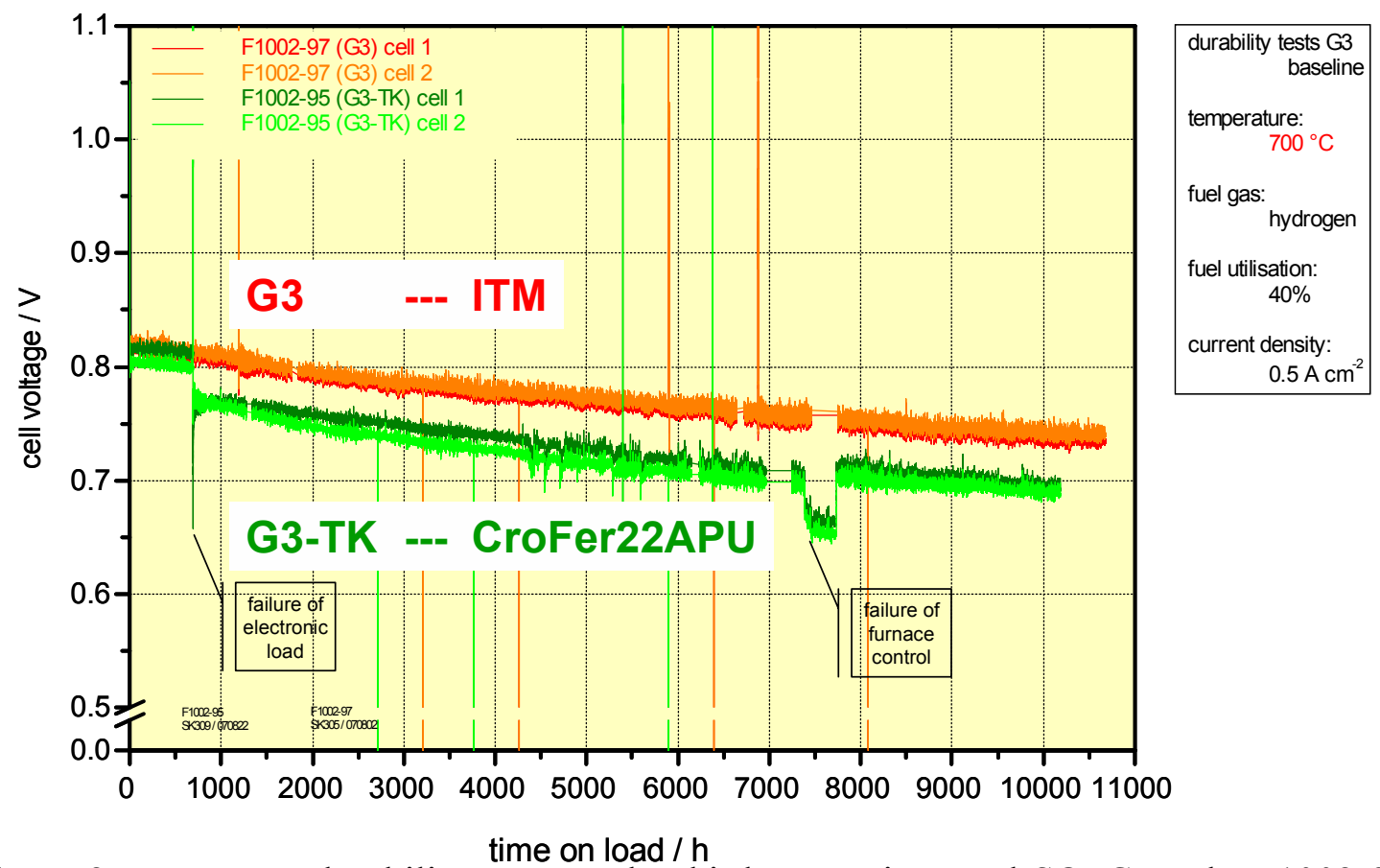

Figure 2. Long-term durability tests on the third generation Real-SOFC stacks F1002-97 (G3), and $-95(\mathrm{G} 3-\mathrm{TK})$ operated at $700^{\circ} \mathrm{C}$ on hydrogen $\left(\mathrm{u}_{\mathrm{F}}=40 \%\right)$ at $0.5 \mathrm{~A} / \mathrm{cm}^{2}$.

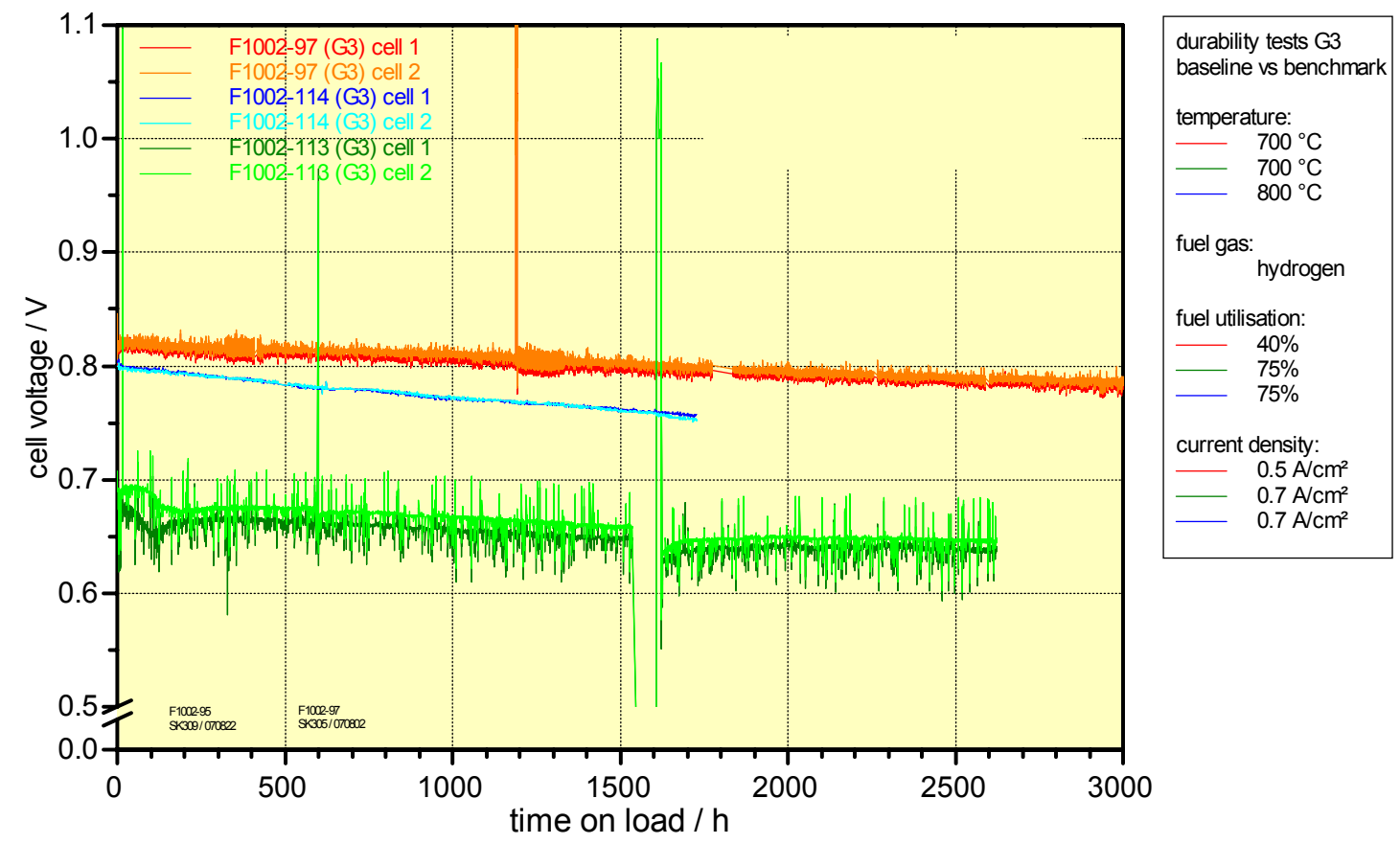

Figure 3. Excerpt from the sensitivity matrix measurements. The top curve corresponds to that of the G3 stack shown in Fig. 2. The second comes from an identical stack run at 700 $\mathrm{mA} / \mathrm{cm}^{2}$ and $800^{\circ} \mathrm{C}$, whereas the third (bottom) curve corresponds to a $\mathrm{G} 3$ stack run at $700 \mathrm{~mA} / \mathrm{cm}^{2}$ and $700^{\circ} \mathrm{C}$. The variance in noise on the three signals is a function of the test rig data acquisition and the technique of supplying moisture to the hydrogen fuel. 
degradation (relative loss of voltage per thousand hours) will deliver misleading values in the comparison of the top and bottom curves. Although the absolute change in voltage is approximately equal, due to the higher current and thus lower voltage with the bottommost stack test curve, the relative change will be higher in this case. For a more detailed discussion of degradation issues see (2).

Stack tests, including thermal cycles, were carried out by FZJ and GDF. FZJ subjected a third generation stack to 34 intermediate thermal cycles (cycling between 800 and $450^{\circ} \mathrm{C}$ ) and 100 deep thermal cycles (between 800 and $100^{\circ} \mathrm{C}$ ). All thermal cycles were carried out with heating and cooling rates of $2 \mathrm{~K} \mathrm{~min}^{-1}$, and natural cooling below $650^{\circ} \mathrm{C}$. A gradual increase in ASR was observed for both cells in the stack as the amount of thermal cycles increased. After conclusion of 134 thermal cycles, the total performance loss was approx. 20\% (Fig. 4).

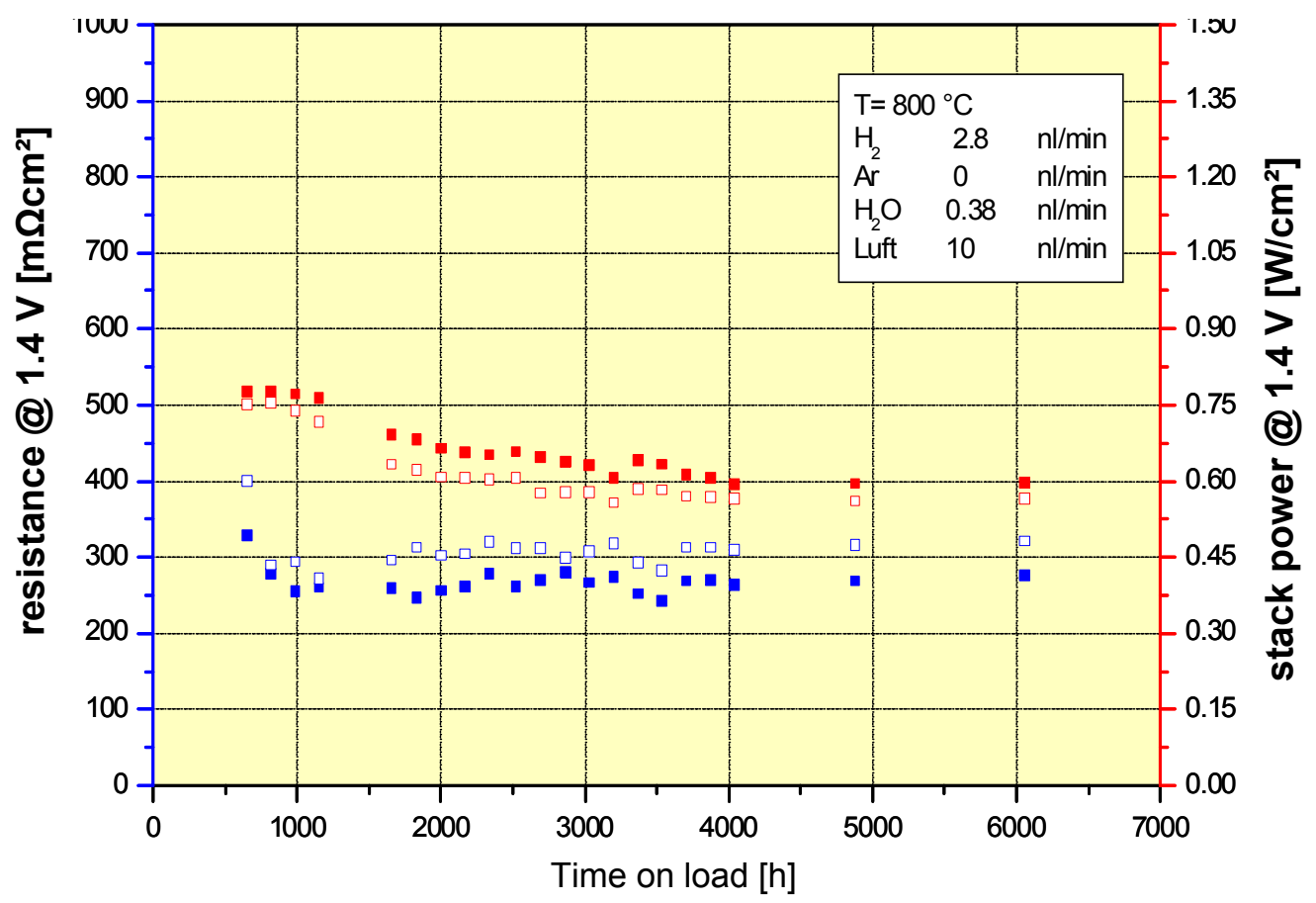

Figure 4. Effect of 100 thermal cycles $\left(100^{\circ} \mathrm{C}\right.$ to $\left.800^{\circ} \mathrm{C}\right)$ on ASR (left axis) and electrical power (right axis) for an FZJ G3 stack. After the initial frequent measurements of ASR these were only taken at intervals of 1000 hours from hour 4000 onwards.

\section{Hexis Technology}

Different generations of Hexis stacks were used in the Real-SOFC project since 2006. These generations correspond to a series of tests conducted at Hexis on a variation of different generation components. In these stacks one or several components were modified: contacting, various generations of MICs, different coatings developed in the frame of the project and different cell generations developed internally at Hexis.

Hexis changed its stack concept in 2004 from the former HXS-1000 to the Galileo type stack. At the same time, different components were modified, e.g. Hexis made a move from the 3 and 2-plate MIC design to the cheaper one-plate concept. This triggered a new learning curve to increase the component reliability and quality. 
The first generation stacks tested in 2006 showed an ASR degradation rate varying around $20 \% / 1000 \mathrm{~h}$ due to poor contacting and bending of the interconnects. The measurements were not reproducible, some having low, some high degradation levels. $2^{\text {nd }}$ generation stacks using improved contacting layers and $2^{\text {nd }}$ generation interconnect materials, of higher quality and lower bending, improved the ASR degradation rate to the level of 6 to $8 \% / 1000 \mathrm{~h}$ and were tested for a period of more than $10000 \mathrm{~h}$. The initial high ASR degradation rates of 8 to $10 \%$ are thought to stem from the rapid parabolic oxidation of the interconnect at $950^{\circ} \mathrm{C}$ leading to thick $\mathrm{Cr}_{2} \mathrm{O}_{3}$ layers of about 20 to $30 \mu \mathrm{m}$ with high resistivity.

With new protective coatings, the degradation rate was cut further. A $\mathrm{Co}_{1.9} \mathrm{Fe}_{0.1} \mathrm{MnO}_{4} / \mathrm{LSM}$ duplex coating allowed to reduce the degradation to a level of $0.6-$ initially - to $2 \%$ - over the whole run - per $1000 \mathrm{~h}$. The test was conducted for $4500 \mathrm{~h}$ and then shut down for post-mortem analysis of the interconnects. This performance was a factor of at least 4 better than with the previous LSM coatings. Coating the interconnect with $\mathrm{Ni}$ on the anode side also allowed to increase the lifetime of the stack by lowering the initial degradation rates to about $5.5 \% / 1000 \mathrm{~h}$ (vs. 8 to 10\%). This is thought to stem from the protection ability of $\mathrm{Ni}$ for $\mathrm{Cr}$-oxide growth on the anode side but also for a higher conductivity of the mixed Ni-Cr-oxide scale. This test was run for $6500 \mathrm{~h}$ and showed that an anode coating on the MIC is also necessary.

Furthermore, by lowering the operating temperature from $950^{\circ} \mathrm{C}$ to $900^{\circ} \mathrm{C}$, the $\mathrm{Cr}$ oxide growth on the interconnect was cut drastically, and with second generation cells (made to allow better performances at lower temperatures) the measured degradation rates were around 0.5 to $2 \% / 1000 \mathrm{~h}$ using the conventional LSM-coating on the cathode side (no coating on the anode side). $3^{\text {rd }}$ generation MICs again had much higher quality, at the same time $3^{\text {rd }}$ generation cells showed higher performances $\left(200 \mathrm{~mW} / \mathrm{cm}^{2}\right.$ at 700 $\mathrm{mV}$ compared to 150 previously).

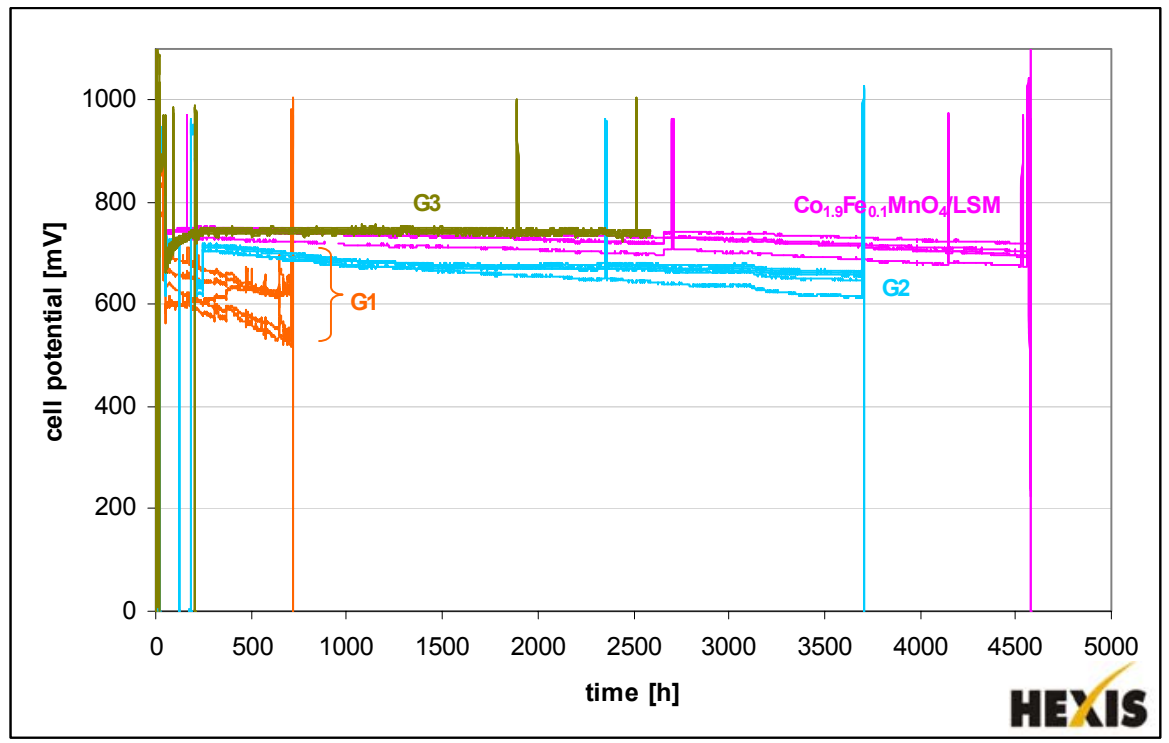

Fig. 5. Evolution of the stack generations presented in the Real-SOFC project (current of 20A) measured under steady state conditions. Each colour corresponds to a 5 cells stack, and each stack has 5 cells represented. The $1^{\text {st }}$ generation stacks showed high variability (non reproducibility). The G1 and the CFM/LSM-Stack were operated at $950^{\circ} \mathrm{C}$, while the $\mathrm{G} 2$ and $\mathrm{G} 3$ stack were run at $900^{\circ} \mathrm{C}$. 


\section{HTceramix Technology}

Within the duration of the Real-SOFC project HTC changed their design from the ' $\mathrm{R}$ ' design without sealing to the ' $\mathrm{S}$ ' design with compressive sealing (G3). The migration towards the G3 design also included abandoning the LSF cathode material in favour of several choices of other cathode materials. The short stacks used for testing had an active area of $50 \mathrm{~cm}^{2}$ per cell and a total number of 5 cells.

Fig. 6 and 7 show results from the most recent testing at VTT using ECN-made LNF cathode cells in a HTC short stack. The total current of 8 and 12 A corresponds to 160 and $240 \mathrm{~mA} / \mathrm{cm}^{2}$, respectively. The LNF cathode cells were not yet able to supply sufficient current at $700 \mathrm{mV}$ to be operated at the standard $500 \mathrm{~mA} / \mathrm{cm}^{2}$ at $800^{\circ} \mathrm{C}$. Further optimisation is clearly needed here.

On the other hand, the comparison of I-V-curves prior to and after 3000 hours of standard testing show little difference on average. LNF cathodes are insensitive to chromium poisoning due to a lack of reactivity of the cathode compounds with chromium. This would eliminate one of the many degradation mechanisms. Inspection of Fig. 7 shows that even a slight activation of the cathode takes place but at the same time the ohmic resistance increases (with the exception of the curve taken at $750^{\circ} \mathrm{C}$ ). Total stack voltage decreased by $0.3 \% / 1000 \mathrm{~h}$ but as can be seen from Fig. 6 , cell performance was not uniform. After approx. 3000 hours a fault in the fuel supply line caused an automatic shut-down of the test rig. After it had been restarted after 20 minutes, cell voltage degraded rapidly and the stack was shut down.

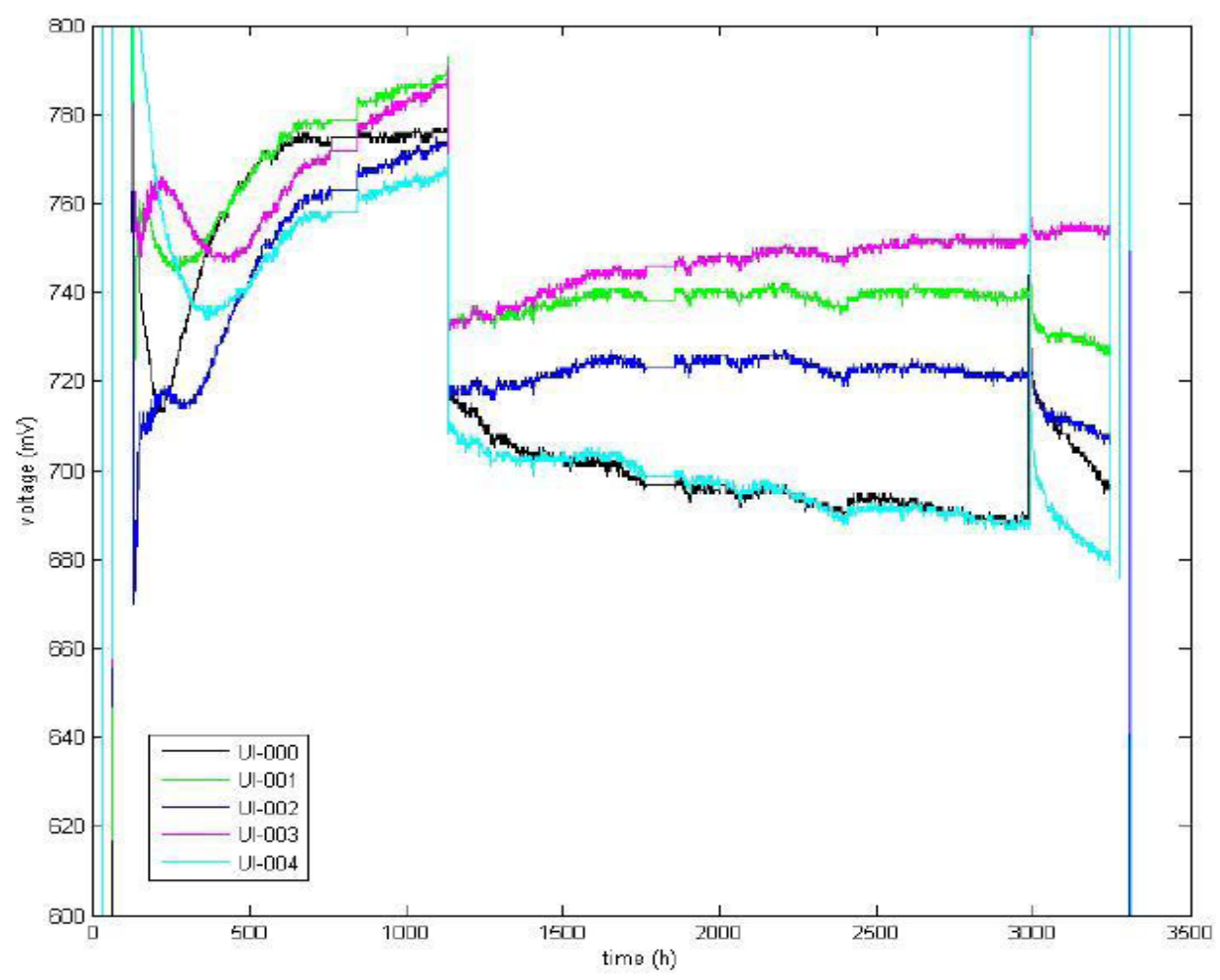

Figure 6. HTceramix S-design short stack cell voltages during 8 A and 12 A constant current tests of 3000 hours duration. The individual voltages of the five cells are shown. 


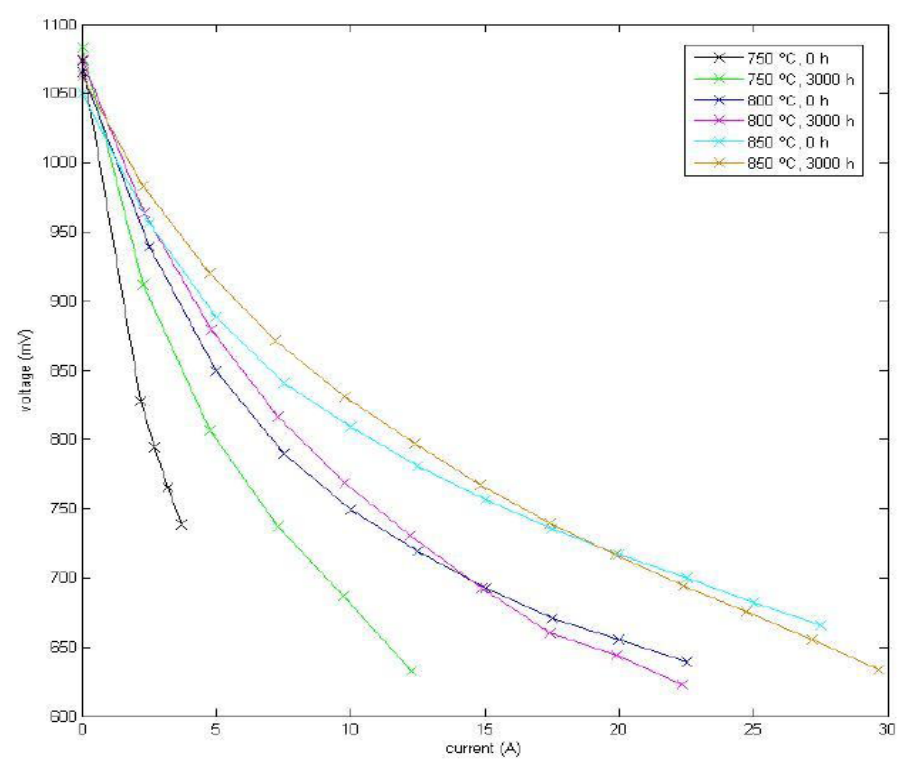

Figure 7. HTceramix short stack with ECN LNF-cathode cells - Average stack polarisation curves at different temperatures before and after the test shown in Fig. 6.

\section{RollsRoyce Fuel Cell Systems Technology}

The main activity of RRFCS within Real-SOFC concerned the integration of alternative electrode materials into the specific RRFCS tube design (performed by the University of St. Andrews) and thermal cycling tests (performed by the University of Birmingham).

The electrode work constitutes a good example of the possibilities given in an Integrated Project with many partners and a broad approach to a given topic, as encouraged in the EU $6^{\text {th }}$ Framework Programme. The first screening of LSCF as a potential cathode material showed that the performance increase to be achieved at lower temperatures (cf. FZJ G3 design) was greatly reduced above $850^{\circ} \mathrm{C}$. Therefore, a switchover to LSCF was considered pointless for RRFCS. The anode material supplied by University of St. Andrews for increasing redox and sulphur tolerance proved impossible to process for anode (ASC) and electrolyte supported cells (ESC) as manufactured by FZJ and ECN due to low sinterability. Within the RRFCS design with thin layers on an inert substrate, it was nevertheless possible to integrate this material and produce tubes for test operation. The variety of designs and operating conditions covered in the project thus allowed to transfer unsuccessful developments from one design to another and also understand better the strong and weak points about materials and component designs.

Considerable effort by University of St. Andrews was necessary in fine tuning and adapting the materials. The process clearly shows that even when materials are characterised as very promising from first laboratory screenings, they might still fail in cell or stack integration. Underperformance of materials integrated into components, on the other hand, might well be due to incomplete understanding of the processing intricacies, operating limits and incomplete optimisation of structure and stoechiometry. In practice, it is difficult to estimate the potential of such a material in being further adapted and the effort necessary in doing so. This will very much depend on the skills and experience of the processing laboratory. 


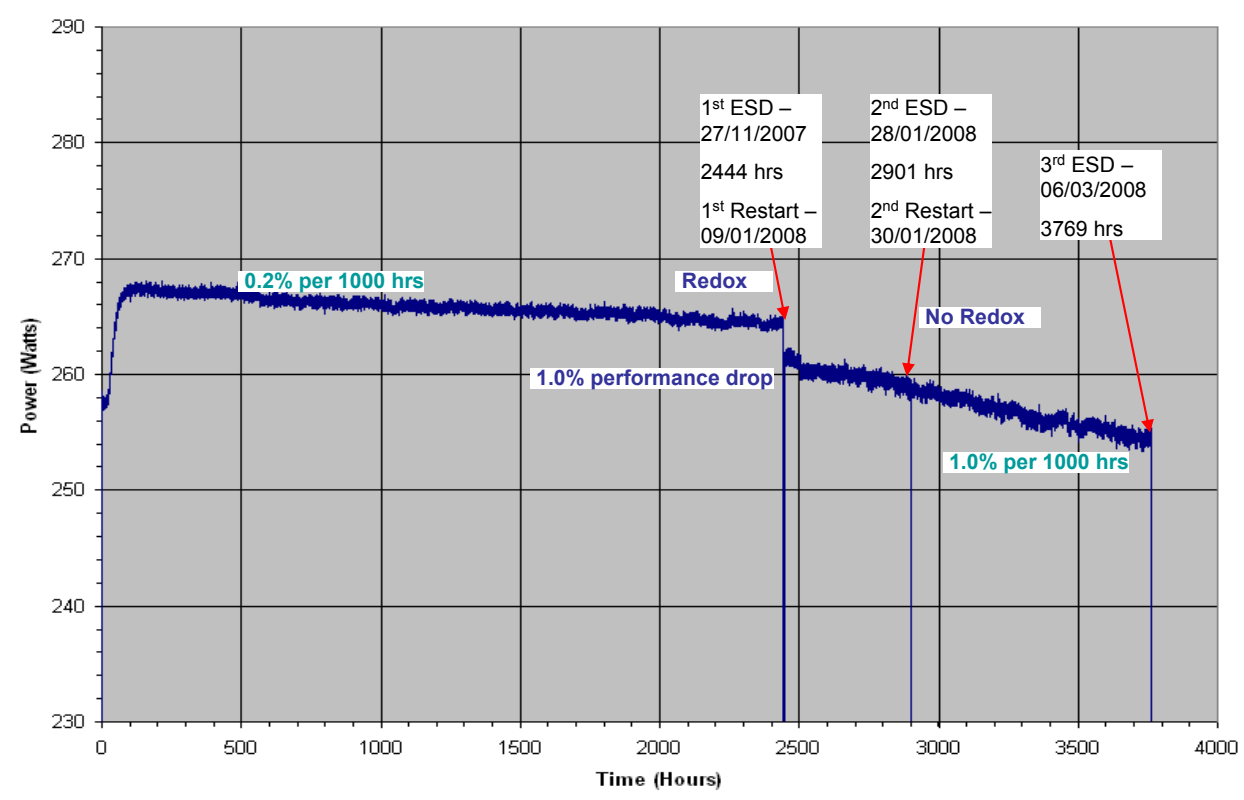

- Bundle Power

Figure 8. Long-term testing on an RRFCS G2 tube bundle. The first set of I-V-curves taken included an involuntary redox cycle (as indicated) and subsequent decrease in voltage. This was avoided during later I-V-curve recordings. Degradation increased from 0.2 to $1 \%$ voltage loss per 1000 hours after the first I-V-reading.

\section{Redox Stability of Anodes}

ECN carried out tests on novel anode materials with a focus on further improvement of the redox stability. The investigated anodes consisted of GDC-Ni functional layers with low nickel content and $\mathrm{Ni}-\mathrm{La}_{0.9} \mathrm{Mn}_{0.8} \mathrm{Ni}_{0.2} \mathrm{O}_{3}$ cermet used as anode current collecting layer. The perovskite that is used in the anode current collecting layer exhibits electrical conductivity under reducing conditions, which allows for reduction of the nickel content and thereby suppression of the nickel sintering. The experiments made clear that reduction of the nickel content in the anode current collecting layer below the nickel percolation threshold did not improve the redox stability (Fig. 9). Post test analysis made clear that nickel sintering occurred during the redox cycling tests, even when the nickel content was below the nickel percolation threshold, and that this is the most likely cause of the observed deactivation of the cell voltage. On basis of the results, an anode with $34 \mathrm{w} \% \mathrm{Ni}$ in the anode functional layer and $70 \mathrm{w} \% \mathrm{Ni}$ in the anode contact layer was selected for G3 ESC cell technology. Further reduction of the nickel content in the anode contact layer could improve the mechanical integrity of this layer, but with dropping absolute electrical conductivity this will not result in improved stability.

For LSCM anodes, the impact of the LSCM layer thickness on the cell performance and redox stability was investigated. The results indicate that the cell performance increases as the LSCM layer thickness increases, which could be attributed to improved lateral conduction within the LSCM electrode. Compared to Ni-based anodes, the performance of the LSCM anode is low. The tests further indicated that thin LSCM layers are better able to withstand redox cycling than thick layers, which indicates that LSCM should be kept thin to allow this electrode material to survive many redox cycles. 


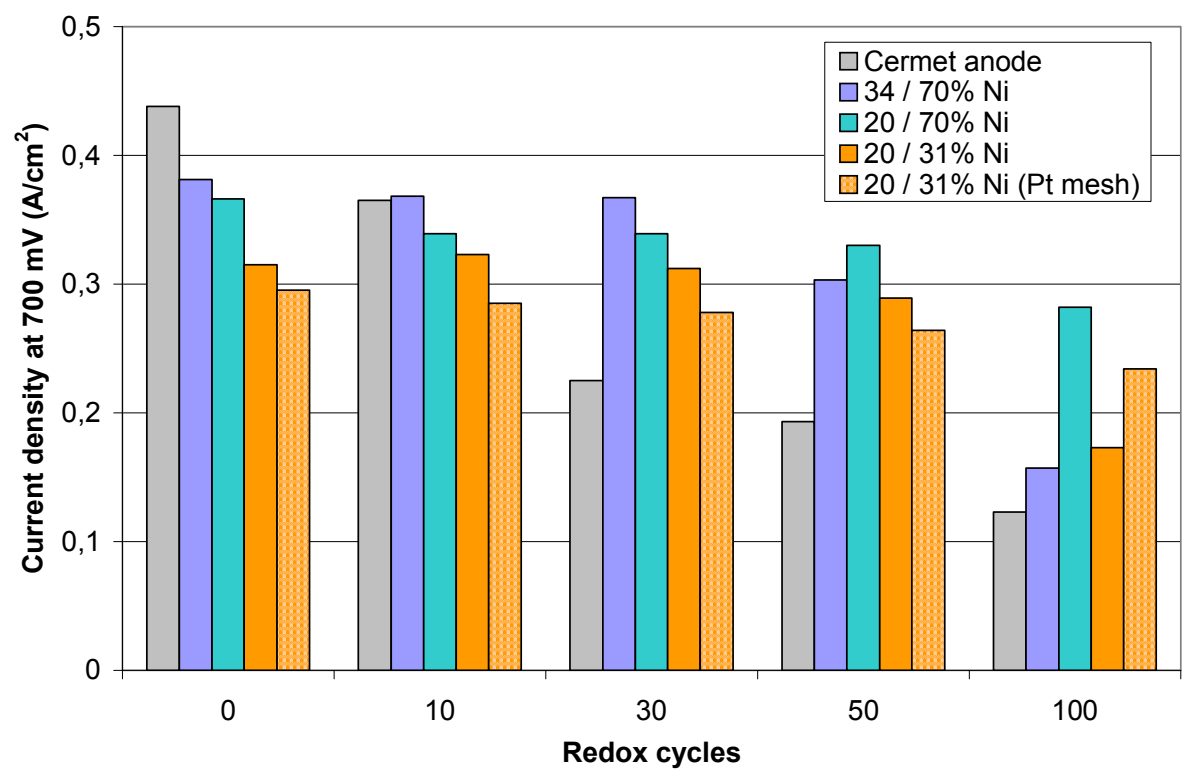

Figure 9. Current density decay during redox cycling tests on ESCs with anode assemblies comprising a GDC-Ni functional layer (nickel content 34 or $20 \mathrm{w} \%$ ) and Ni$\mathrm{Ni}-\mathrm{La}_{0.9} \mathrm{Mn}_{0.8} \mathrm{Ni}_{0.2} \mathrm{O}_{3}$ contact layer (70 or $31 \mathrm{w} \%$ nickel content). Conditions: single cell test-rig with nickel mesh for anode current collection, $\mathrm{H}_{2}-\mathrm{H}_{2} \mathrm{O}$ 50:50 fuel.

HEXIS $1^{\text {st }}$ generation stacks degraded by about $30-40 \%$ after 4 redox cycles. $2^{\text {nd }}$ generation stacks were able to withstand at least 10 cycles before reaching a high degradation level. Tests in ideal set-ups showed that the anode withstands at least 30 cycles before the degradation sets in definitively, even 50 cycles before the degradation reaches $40-50 \%$ ASR degradation.

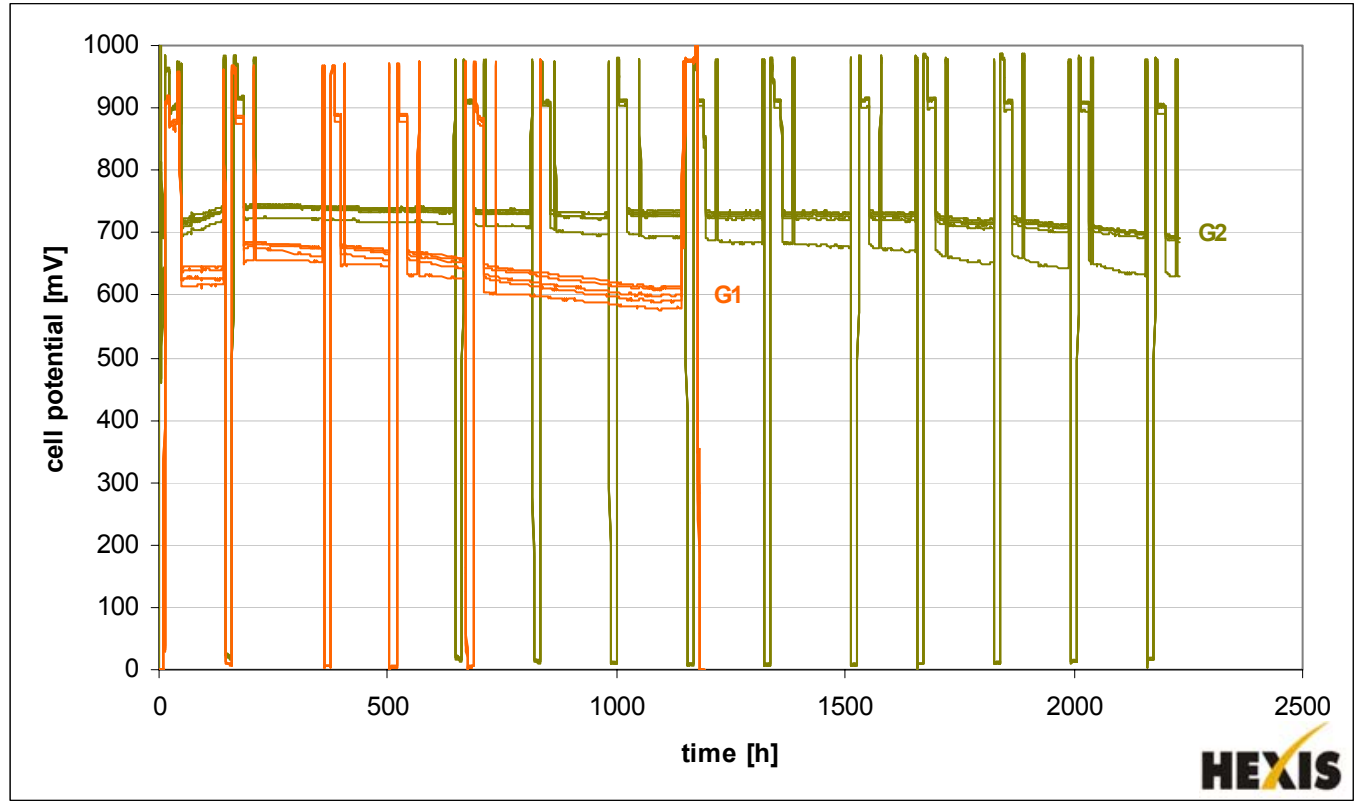

Figure 10. Comparison of redox-tests performed on Hexis G1 and G2 stacks (current of 20A). Each graph corresponds to a 5 cells stack, and each stack has 5 cells represented. The $1^{\text {st }}$ generation stacks showed increased degradation after 4 redox cycles; the $2^{\text {nd }}$ generation withstands 10 cycles before the degradation sets in (here 11 cycles are represented). In this test $24 \%$ ASR degradation are measured after 11 cycles. 


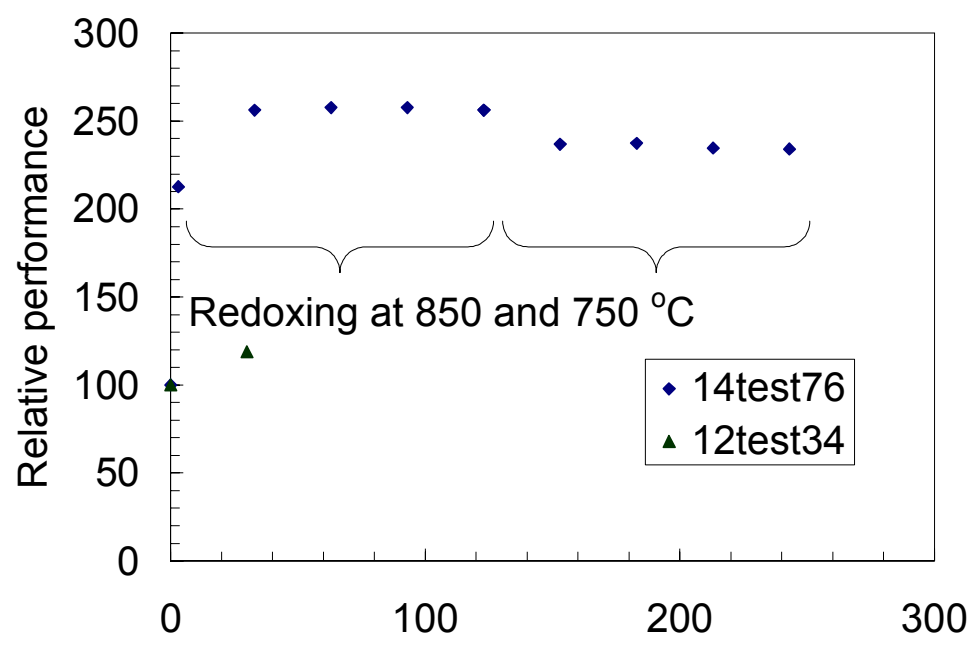

Figure 11 . Redox cycling behaviour of cells with STN anode at $850^{\circ} \mathrm{C}$ and $750^{\circ} \mathrm{C}$. The $\mathrm{X}$-axis shows the number of cycles performed. The cells show a slight activation after the first redox cycles, followed by a very stable operation through the following cycles.

Risø-DTU investigated the redox cycling behaviour of novel anode materials composed of SrTiNb. Risø carried out redox cycling tests on electrolyte supported cells. One of these cells was subjected to more than 200 redox cycles by flushing the anode compartment with air, first at $850^{\circ} \mathrm{C}$ and later on at $750^{\circ} \mathrm{C}$. From Fig. 11 it can be seen that the cell initially activated by a factor of 2 . After this activation, the cell showed no signs of deactivation due to redox cycling, indicating good stability of STN. However, the performance of the anode is comparatively low, and should be improved by at least a factor of 5 to 10 .

\section{High-Performance Cathodes}

One of the main activities in the materials development part of the project was to select cathode materials with high performance at low temperatures. Since most degradation mechanisms are temperature driven, a reduction in operating temperature will generally reduce overall stack degradation. As shown above already, the implementation of LSCF cathodes in the FZJ G3 design allowed for a reduction of operating temperature from $800^{\circ} \mathrm{C}$ to $700^{\circ} \mathrm{C}$ whilst attaining the same output power level as with the G1/G2 cathodes (LSM). The tests resulted in markedly reduced degradation.

Fig. 12 shows cell voltages from a TOFC 11-cell stack incorporating a selection of four different cathodes supplied by FZJ: PSCF, LSCCF (2 stoechiometries), and LSCF, and TOFC standard LSM cells. Surprisingly, the PSCF cathode provided a noticeably higher voltage than the LSCF cathode and also showed less degradation. The two LSCCF cathodes (with copper part-substitution) displayed similarly increased performance. After addition of water to the cathode gas stream (simulating moisture saturated air at room temperature) the LSM cathode (not shown in Fig. 12) showed rapid degradation which the other cathodes did not. While the LSCF cathode cell degraded by about $1 \%$ of voltage per 1000 hours, the PSCF and LSCCF cathode cells showed no perceptible degradation over the first 100 hours of the test. Work will be further continued to evaluate the alternative cathode materials' performance in stacks. 


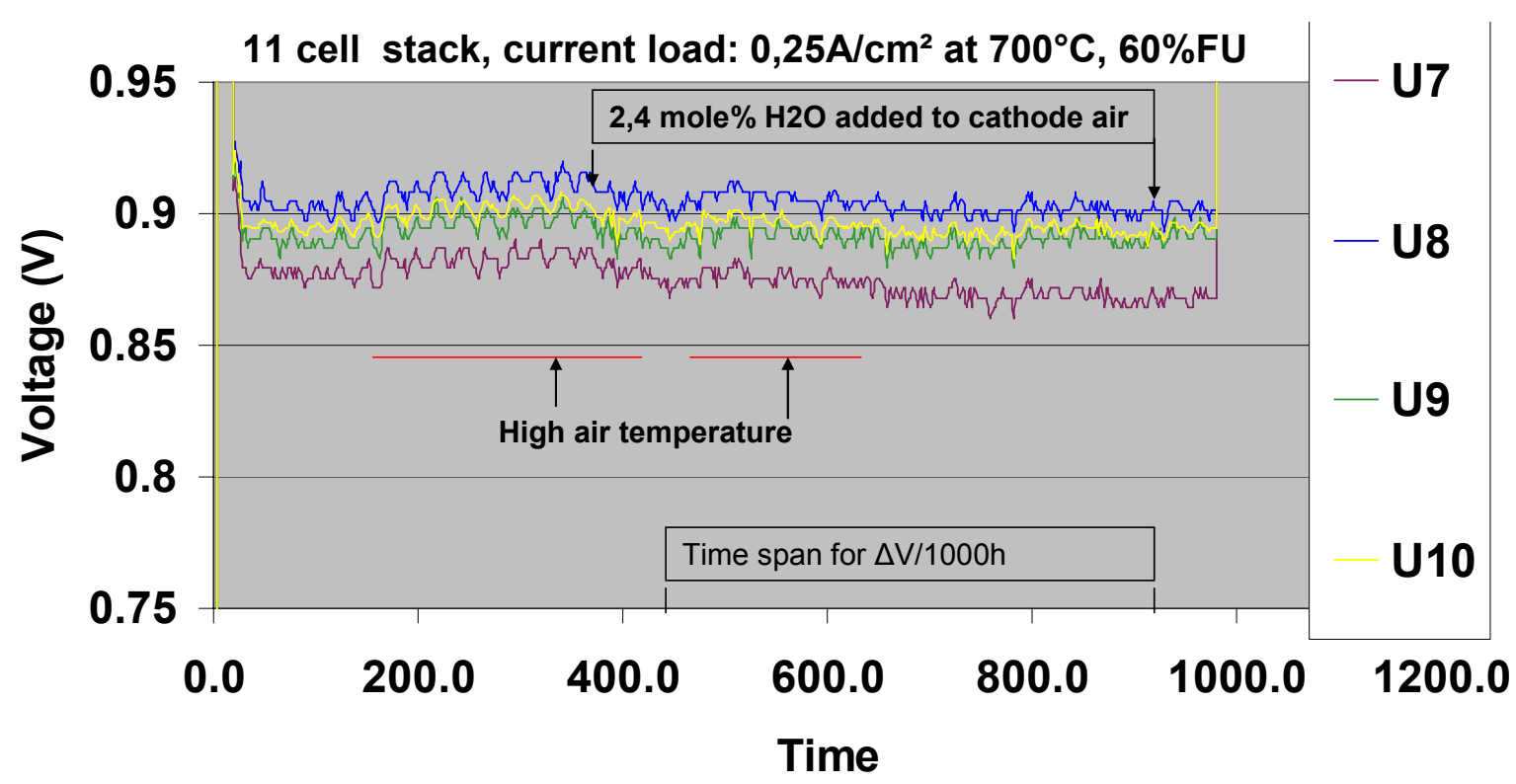

Figure 12. Cell voltages taken from a TOFC stack with 11 cells, mixing different cells with FZJ-supplied cathodes. U7 corresponds to an LSCF cathode cell, U8 to a PSCF cathode and U9/U10 to two different LSCCuF cathodes.

\section{Project Conclusions}

The project successfully achieved all proof-of-concept testing. This especially included:

- $>10000$ hour test on two FZJ Generation 3 (G3) stacks (still ongoing at time of writing and achieving approx. 15000 hours by the end of April 2009)

- $>100$ thermal cycles on an FZJ G3 stack from room temperature to $800^{\circ} \mathrm{C}$

- 250 full redox cycles on SrTi-anode ESC cells with extremely low performance degradation

- avoidance of coking at low water levels with gold and silver impregnated anodes (not discussed in this paper).

This said, considerable progress has been made in comparison to the status at the beginning of the project in February 2004. Whilst degradation rates were 2 to 3\% of voltage drop per 1000 hours of operation at $300 \mathrm{~mA} / \mathrm{cm}^{2}$ at that time, the stacks now degrade at a rate of around 0.5 to $0.75 \% / 1000 \mathrm{~h}$, but at a load level as high as $500 \mathrm{~mA} / \mathrm{cm}^{2}$. According to the surveys performed in 2006 on testing conditions, this is well above the envisaged operating ranges of early commercial adopters, by a factor of 2 to 3. This underlines the statement that - given continuous operation - SOFC stacks could be operated for well above 30000 hours at 'mild' operating conditions before losing a total of 10 to $20 \%$ of beginning-of-life performance. This would allow first commercial applications in the stationary power markets. 
These results were achieved primarily by applying up-to-date steels with protective coatings, up-to-date cathodes and by optimising specific properties of the stacks.

Outside of the long-term tests, improvements of composition of materials and choice of electrode materials influenced by project results led to greatly improved long-term performance of stacks from the manufacturers TOFC, Hexis, HTceramix and RRFCS.

The aspect of understanding of degradation, in contrast, was less successfully solved. A rather in-depth analysis was performed on deterioration of cell performance by chromium (3) and sulphur influences (4), though. The effects proved very complex and especially in the case of chromium the stack test results could only in part be explained by the analytical results. This work is now ongoing on the basis of more detailed and specific experiments at FZJ.

As far as new materials developments went, the developments within Real-SOFC did not render "break-throughs". Many of the materials entered into the R\&D programme by the partners when writing the proposal did not prove to be superior to the solutions known and used at the start of the project (state-of-the-art, 'Generation 1' components). This supports the impression that materials are currently less of an issue with SOFC performance improvement than the processing of the materials and layers, which in the end have more influence on performance and lifetime than the materials themselves. Nevertheless, the materials entered into the project as at-the-time (2003/2004) recent developments (ITM steel, LSCF cathodes) have now been extensively characterised and constitute the mainstay of Generation 3, allowing major improvements in stack durability. The only exceptions to this general picture are the PSCF and LSCCF cathodes which were developed and evaluated during the project, the MCF protective coatings temporarily abandoned after having under-performed in a first test, and the SrTiNbanodes only successfully integrated into cells towards the end of the project.

It also seems that it is difficult to match conflicting requirements in SOFC components. This is most evident with the new anode materials where improved redox stability, sulphur or coking tolerance went hand in hand with a low electrochemical performance. This could partly be remedied by optimised processing and tailoring of microstructures. In some cases (LSCM), though, this work still needs to be concluded.

Although much criticism has been aired about the 'over sized' Integrated Projects it must be stated that Real-SOFC was successful in building a network of closely cooperating European players. The trust and understanding generated within the project lead the partners on into many cooperation project proposals integrating several manufacturers or players. Compared to the smaller projects (STReP etc.) the group could react more flexibly and the output was more meaningful and accessible to a larger grouping of stakeholders. Small projects, though definitely more targeted, suffer from the limitations of IPR-sharing and the transferability of results to other designs and technologies. It is therefore suggested, that large projects collecting expertise across a large number of partners thus building critical mass and establishing closely collaborating networks, be again supported by the European funding schemes. 


\section{Acknowledgments}

The authors wish to thank all partners in the Real-SOFC project for their continued support and the excellent cooperation. They also thank the European Commission for cofinancing the project under the contract number SES6-CT-2003-502612.

\section{References}

1. L. Blum, H.-P. Buchkremer, S. M. Gross, L. G. J. de Haart, J. Quadakkers, U. Reisgen, R. Steinberger-Wilckens, R. W. Steinbrech, F. Tietz, Int. J. Appl. Ceramic. Technology 3 [6], 470-476 (2006).

2. L. G. J. de Haart, J. Mougin, O. Posdziech, J. Kiviaho, N. H. Menzler, Proc. 8th Europ. SOFC Forum, Lucerne, CD-ROM, B1002 (2008).

3. N. H. Menzler, et. al., Proceedings of the 10th International Symposium on Solid Oxide Fuel Cells (SOFC-X), ECS Transactions 7[1], 245 - 254 (2007).

4. A. Braun, M. Janousch, J. Sfeir, J. Kiviaho, M. Noponen, F. E. Huggins, M. J. Smith, R. Steinberger-Wilckens, P. J. Holtappels, J. Power Sources (in print) (2009). 